\title{
Elongational viscosity of rubber compounds and improving corresponding models
}

\author{
Perko, L. ${ }^{a}{ }^{,}$, Friesenbichler, $\mathbf{W} .{ }^{a}$, Obendrauf, W. ${ }^{b}$, Buchebner, V. $^{a}$, Chaloupka, G. ${ }^{a}$ \\ ${ }^{a}$ Chair of Injection Moulding of Polymers, Department Polymer Engineering and Science, Montanuniversität Leoben, Otto- \\ Gloeckel Strasse 2, 8700 Leoben, Austria \\ ${ }^{\mathrm{b}}$ Shell UK Limited, London SE1 7NA, London, United Kingdom
}

\begin{abstract}
A B S T R A C T
As good as the topic of elongational viscosity is covered by scientific work on thermoplastics, as little research has been done on rubber compounds. This paper focuses on the elongational properties of an SBR rubber compound using different measurement methods. First measurements were made on a Sentmanat Extensional Rheometer (SER). This method is limited to elongation rates up to $20 \mathrm{~s}^{-1}$. Higher elongation rates (up to $300 \mathrm{~s}^{-1}$ ) can be covered with a High Pressure Capillary Rheometer (HPCR), where Cogswell's and Binding's models were used. The simplifications of these methods were precisely depicted and their influence on the results was evaluated. For further improvement of Cogswell's method a previously unreleased method by Obendrauf was applied using two different laws for the approximation of shear viscosity which is essential for the calculation of elongational viscosity. The calculated elongational viscosities could be ascertained using an orifice die for the refinement of the inlet pressure measurements. Finally, the elongational viscosity curves from the HPCR were compared with the SER-viscosity data and a good correlation could be found. This suggests that elongational viscosity ascertained from converging flow measurements is comparable to SER measurements, which would be of great practical use hence HPCRs are available at many laboratories.
\end{abstract}

\section{ARTICLE INFO}

Keywords:

Elongational viscosity

Extensional viscosity

Converging flow

Sentmanat extensional rheometer

Rubber compound

*Corresponding author:

leonhard.perko@unileoben.ac.at

(Perko, L.)

\section{References}

[1] Trouton, F.T. (1906). On the coefficient of viscous traction and its relation to that of viscosity, Proceedings of the Royal Society, Vol. 77, No. 519, 426-440.

[2] Meissner, J. (1969) Rheometer zur Untersuchung der deformationsmechanischen Eigenschaften von KunststoffSchmelzen unter definierter Zugbeanspruchung, Rheologica Acta, Vol. 8, No.1, 78-88, doi: 10.1007/BF02321358.

[3] Meissner, J., Hostettler, J. (1994). A new elongational rheometer for polymer melts and other highly viscoelastic liquids, Rheologica Acta, Vol. 33, No. 1, 1-21, doi: 10.1007/BF00453459.

[4] Maja, J.M., Covas, J.A., Nóbrega, J.M., Dias, T.F., Alves, F.E. (1999). Measuring uniaxial extensional viscosity using a modified rotational rheometer, Journal of Non-Newtonian Fluid Mechanics, Vol. 80, No. 2-3, 183-197, doi: 10.1016/S0377-0257(98)00086-X.

[5] Münstedt, H. (1979). New universal extensional rheometer for polymer melts. Measurements on a polystyrene sample, Journal of Rheology, Vol. 23, No. 4, 421-436, doi: 10.1122/1.549544.

[6] McKinley, G.H., Sridhar, T. (2002). Filament-stretching rheometry of complex fluids, Annual Reviews of Fluid Mechanics, Vol. 34, No. 34, 375-415, doi: 10.1146/annurev.fluid.34.083001.125207.

[7] Sentmanat, M. (2004). Miniature universal testing platform: from extensional melt rheology to solid-state deformation behaviour, Rheologica Acta, Vol. 43, No. 6, 657-669, doi: 10.1007/s00397-004-0405-4.

[8] Cogswell, F.N. (1972). Converging flow of polymer melts in extrusion dies, Polymer Engineering and Science, Vol. 12, No. 1, 64-73, doi: 10.1002/pen.760120111. 
[9] Binding, D.M. (1988). An approximate analysis for contraction and converging flows, Journal of Non-Newtonian Fluid mechanics, Vol. 27, No. 2, 173-189, doi: 10.1016/0377-0257(88)85012-2.

[10] Aho, J., Rolón-Garrido, V.H., Syrjälä, S., Wagner, M.H. (2010). Extensional viscosity in uniaxial extension and contraction flow - Comparison of experimental methods and application of the molecular stress function model, Journal of Non-Newtonian Fluid Mechanics, Vol. 165, No. 5-6, 212-218, doi: 10.1016/j.jnnfm.2009.12.003.

[11] Mackay, M.E., Astarita, G. (1996). Analysis of entry flow to determine elongation flow properties revised, Journal of Non-Newtonian Fluid Mechanics, Vol. 70, No. 3, 219-235, doi: 10.1016/S0377-0257(96)01540-6.

[12] Obendrauf, W. (1996). Neue Methoden zur Temperatur- und Dehnviskositätsmessung für die Simulation von Kunststoffverarbeitungsprozessen, $\mathrm{PhD}$ thesis, Institute of Polymer Processing, MontanuniversitätLeoben, Austria.

[13] Zatloukal, M., Vlcek, J., Tzoganakis, C., Sáha, P. (2002). Improvement in techniques for the determination of extensional rheological data from entrance flows: computational and experimental analysis, Journal of NonNewtonian Fluid Mechanics, Vol. 107, No. 1-3, 13-37, doi: 10.1016/S0377-0257(02)00111-8.

[14] Bersted, B.H. (1993). Refinement of the converging flow method of measuring extensional viscosity in polymers, Polymer Engineering and Science, Vol. 33, No. 16, 1079-1083, doi: 10.1002/pen.760331610.

[15] Leblanc J.L. (2002). Rubber-filler interactions and rheological properties in filled compounds, Progress in Polymer Science, Vol. 27, No. 4, 627-687, doi: 10.1016/S0079-6700(01)00040-5.

[16] Barrés, C., Leblanc, J.L. (2000). Recent developments in shear rheometry of uncured rubber compounds: I. Design, construction and validation of a sliding cylinder rheometer, Polymer Testing, Vol. 19, No. 2, 177-191, doi: 10.1016/S0142-9418(98)00090-7

[17] Shin, K.C., White, J.L., Nakajima, N. (1990). Extrudate character and post-extrusion shrinkage of rheologically characterized rubber-carbon black compounds and their interpretation, Journal of Non-Newtonian Fluid Mechanics, Vol. 37, No. 1, 95-108, doi: 10.1016/0377-0257(90)80005-K.

[18] Sridhar, T. (1990). An overview of the project M1, Journal of Non-Newtonian Fluid Mechanics, Vol. 35, No. 2-3, 8592, doi: 10.1016/0377-0257(90)85039-2.

[19] James, D.F., Walters, K. (1994). A critical appraisal of available methods for the measurements of extensional properties of mobile systems, In: Collyer, A.A. (ed.), Techniques of Rheological Measurement, Elsevier, New York 33-53. 